RESEARCH ARTICLE

\title{
Chemical composition and lipoxygenase inhibitory activity of Alseodaphne peduncularis Meisn. essential oil
}

\author{
Wan Mohd Nuzul Hakimi Wan Salleh ${ }^{1, *}$ (D) Mohd Azlan Nafiah ${ }^{1, *}$, (D) Shamsul Khamis ${ }^{2}$, (D) Salam \\ Ahmed Abed ${ }^{3}$ \\ ${ }^{1}$ Department of Chemistry, Faculty of Science and Mathematics, Universiti Pendidikan Sultan Idris, 35900 Tanjung \\ Malim, Perak, MALAYSIA \\ ${ }^{2}$ Department of Biological Sciences and Biotechnology, Faculty of Science and Technology, Universiti Kebangsaan \\ Malaysia, 43600 Bangi, Selangor, MALAYSIA \\ ${ }^{3}$ Department of Pharmacognosy, College of Pharmacy, Kerbala University, IRAQ
}

*Corresponding author. Email: wmnhakimi@fsmt.upsi.edu.my; azlan@fsmt.upsi.edu.my

Submitted: 11.02.2021; Accepted: 20.04.2021

\begin{abstract}
This study examined the chemical composition of the essential oil extracted from the bark of Alseodaphne peduncularis Meisn. (Lauraceae) by hydrodistillation with $0.2 \%$ yield. The essential oil was chemically characterised by gas chromatography-flame ionization detector and gas chromatography-mass spectrometry, and 31 constituents comprising $94.3 \%$ of the total oil content were identified. These constituents included $\beta$-caryophyllene (24.5\%), viridiflorol (12.3\%), $\delta$-cadinene (9.8\%), and bicyclogermacrene (4.2\%), respectively. The tested essential oil showed moderate in vitro lipoxygenase activity with an $\mathrm{IC}_{50}=60.2 \mu \mathrm{g} / \mathrm{mL}$. To the best of our knowledge, there is no report and study on the bark part of this species.
\end{abstract}

Keywords: Lauraceae, Alseodaphne peduncularis, hydrodistillation, GC-MS, lipoxygenase

\section{Introduction}

The tree species Alseodaphne peduncularis Meisn. (Lauraceae), locally known as medang, occurs widely in mixed dipterocarp and sub-montane forests up to $1000 \mathrm{~m}$ above sea level in the Peninsular Malaysia, Sumatra, and Borneo (Turner, 1995; Thakur et al., 2012). Although the tree is a common wood source for fuel, furniture, house, and boat-building, little is known about its medicinal values. Recently, the chemical composition and biological activity of the essential oil extracted from the leaves of $A$. peduncularis were reported in our study (Salleh et al., 2016a). The leaf oil was weak in the DPPH radical scavenging (IC 50 : 253.2 $\mu \mathrm{g} / \mathrm{mL}$ ) with relatively low phenolic content $(32.5 \mathrm{mg} \mathrm{GA} / \mathrm{g}$ ) and modest inhibitory effect against acetylcholinesterase (I: 45.2\%) and butyrylcholinesterase (IC 50 : 48.6\%). In the continuation of our studies on essential oils from this species $A$. peduncularis, herein we report the chemical constitution of essential oil extracted from its bark and the lipoxygenase inhibitory effect of the essential oil.

\section{Materials and Methods}

\section{Plant material and isolation of essential oil}

In this study, the essential oil was extracted from the fresh bark of $A$. peduncularis, which was sampled from the secondary forest at Behrang, Perak in September 2019. The tree was taxonomically identified by Shamsul Khamis from Universiti Kebangsaan Malaysia (UKM). Meanwhile, voucher specimens of the plant (SK128/19) were stowed at UKMB Herbarium. A Clevenger apparatus was used to extract the essential oil from the fresh bark (200 g) mixed with water via hydrodistillation for $4 \mathrm{~h}$. The essential oil was desiccated using the dry magnesium sulfate and kept at $4-6{ }^{\circ} \mathrm{C}$ until analysis. 


\section{Analysis of essential oil}

Hydrocarbons were detected via a gas chromatography-flame ionization detector (Agilent Technologies 7890B, USA) equipped with an HP-5MS capillary column of $30 \mathrm{~m}$ in length, $0.25 \mu \mathrm{m}$ thick, and an inner diameter of $0.25 \mathrm{~mm}$. Analytes were moved through the column by helium gas at a flow rate of $0.7 \mathrm{~mL} / \mathrm{min}$. Temperatures were adjusted to $250{ }^{\circ} \mathrm{C}$ and $280^{\circ} \mathrm{C}$ for the injector and detector, respectively, while the oven was set at $50{ }^{\circ} \mathrm{C}$, but slowly increased to $280{ }^{\circ} \mathrm{C}$ at $5{ }^{\circ} \mathrm{C} / \mathrm{min}$ and eventually kept isothermally for $15 \mathrm{~min}$. Samples were diluted with diethyl ether at 1: $100(\mathrm{v} / \mathrm{v})$ and analyzed in triplicates, in which $1.0 \mu \mathrm{L}$ of the diluted sample was manually interpolated at a split ratio of 50: 1 . The average of triplicates was calculated to generate the percentage of peak area. Meanwhile, a gas chromatography-mass spectrometer (GC/MS; 5890A for GC, 5898A for MS, Hewlett Packard, USA) was used to detect various substances in the test sample. Analytes were moved by helium through the HP-5 column fixed to the GC at $1 \mathrm{~mL} / \mathrm{min}$. The injector was kept at $250{ }^{\circ} \mathrm{C}$, and the oven set to gradually increase from 50 to $280^{\circ} \mathrm{C} \mathrm{(5} \mathrm{min} \mathrm{hold)} \mathrm{at} 10{ }^{\circ} \mathrm{C} / \mathrm{min}$ and eventually kept isothermally for $15 \mathrm{~min}$. An electron ionization energy of $70 \mathrm{eV}$ was employed in the GC/MS detection at a scan rate of $0.5 \mathrm{~s}$ (cycle time: $0.2 \mathrm{~s}$ ), encompassing a mass range of 50 - 400 atomic mass unit (Salleh et al., 2012; Salleh et al., 2016b).

\section{Identification of constituents}

For the identification of chemical constituents in GC/MS, samples were co-injected with the standards (major components) with the corresponding retention indices and mass spectra following the study of Adams (2007). Constituents of essential oil were semi-quantified through the normalization of peak areas by taking into account the same reactionary component for all the detected volatile constituents. The average of three $\mathrm{GC}$ analyses yielded the relative percentage (\%) value.

\section{Lipoxygenase inhibitory activity}

The LOX inhibition was largely based on the technique of Ellman (Salleh et al., 2016c), in which $5 \mu \mathrm{L}$ of essential oil was buffered with $1.74 \mathrm{~mL}$ borate $(0.2 \mathrm{M}, \mathrm{pH} 9.2)$ and added with $5 \mu \mathrm{L}(50,000 \mathrm{U} / \mathrm{mL}) \mathrm{of} 5-\mathrm{LOX}$ enzyme. The reaction began upon adding $250 \mu \mathrm{L}$ linoleic acid $(5 \mathrm{mg}$ linoleic acid mixed with $15 \mu \mathrm{L}$ ethanol and $15 \mathrm{~mL}$ borate in brisk shaking). The absorbance at $234 \mathrm{~nm}$ was assayed for $5 \mathrm{~min}$ in a UV-visible spectrophotometer (Genesys 10Se, Thermo Scientific, USA). The dimethyl sulfoxide (5 $\mu \mathrm{L}$ ) served as a negative control, while the quercetin (Sigma-Aldrich, St. Louis, MO, USA), a positive control, was prepared in the same strength as the essential oil. The percentage inhibition (I\%), which is equivalent to the concentration of drug required for $50 \%$ inhibition $\left(\mathrm{IC}_{50}\right)$ in $\mu \mathrm{g} / \mathrm{mL}$, was computed by the equation below:

$$
I \%=\left[A_{\text {initial activity }}-\left(A_{\text {inhibitor }} / A_{\text {initial activity }}\right)\right] \times 100
$$

where $A_{\text {initial activity }}$ is the absorbance of the control, and $A_{\text {inhibitor }}$ is the absorbance of the test sample. Averaging the absorbance values of the triplicates and quercetin yielded the LOX inhibitory activity.

\section{Results and Discussion}

The bark of $A$. peduncularis yielded $0.2 \%$ yellow oil based on the fresh weight. Table 1 shows, in order of elution, 31 constituents identified in the essential oil, comprising $94.3 \%$ of the total chemical content. Sesquiterpenes were the main hydrocarbon groups found in the 16 oil components identified, constituting $59.2 \%$ of the total oil content. Besides, oxygenated sesquiterpenes, oxygenated monoterpenes, and monoterpene hydrocarbons contributed $25.7 \%, 5.7 \%$, and 3.7\%, respectively to the overall oil content. 
Table 1. Chemical composition of Alseodaphne peduncularis essential oil

\begin{tabular}{|c|c|c|c|c|c|c|}
\hline No & $\mathbf{R R I ^ { \mathbf { a } }}$ & $R R I^{b}$ & Components & & Percentage $^{c}$ & Identifications $^{d}$ \\
\hline 1 & 935 & 935 & $\alpha$-Pinene & & $2.0 \pm 0.1$ & $\mathrm{RI}, \mathrm{MS}$ \\
\hline 2 & 945 & 946 & Camphene & & $1.2 \pm 0.1$ & RI, MS \\
\hline 3 & 967 & 965 & Sabinene & & $0.5 \pm 0.2$ & $\mathrm{RI}, \mathrm{MS}$ \\
\hline 4 & 1082 & 1082 & Linalool & & $1.2 \pm 0.1$ & $\mathrm{RI}, \mathrm{MS}$ \\
\hline 5 & 1175 & 1175 & Terpinen-4-ol & & $2.3 \pm 0.2$ & $\mathrm{RI}, \mathrm{MS}$ \\
\hline 6 & 1185 & 1189 & $\alpha$-Terpineol & & $2.2 \pm 0.1$ & $\mathrm{RI}, \mathrm{MS}$ \\
\hline 7 & 1352 & 1350 & $\alpha$-Cubebene & & $1.2 \pm 0.2$ & $\mathrm{RI}, \mathrm{MS}$ \\
\hline 8 & 1374 & 1374 & $\alpha$-Copaene & & $0.2 \pm 0.2$ & $\mathrm{RI}, \mathrm{MS}$ \\
\hline 9 & 1385 & 1386 & $\beta$-Cubebene & & $0.5 \pm 0.1$ & $\mathrm{RI}, \mathrm{MS}$ \\
\hline 10 & 1409 & 1405 & $\alpha$-Cedrene & & $0.2 \pm 0.2$ & $\mathrm{RI}, \mathrm{MS}$ \\
\hline 11 & 1425 & 1420 & $\beta$-Caryophyllene & & $24.5 \pm 0.2$ & $\mathrm{RI}, \mathrm{MS}$, Std \\
\hline 12 & 1455 & 1453 & $\alpha$-Humulene & & $0.5 \pm 0.2$ & RI, MS \\
\hline 13 & 1458 & 1458 & Aromadendrene & & $2.5 \pm 0.1$ & $\mathrm{RI}, \mathrm{MS}$ \\
\hline 14 & 1478 & 1480 & Germacrene D & & $5.2 \pm 0.2$ & RI, MS, Std \\
\hline 15 & 1485 & 1482 & $\alpha$-Amorphene & & $3.5 \pm 0.2$ & $\mathrm{RI}, \mathrm{MS}$ \\
\hline 16 & 1495 & 1495 & Cadina-1,4-diene & & $1.2 \pm 0.1$ & RI, MS \\
\hline 17 & 1500 & 1501 & Bicyclogermacrene & & $4.2 \pm 0.2$ & RI, MS, Std \\
\hline 18 & 1502 & 1500 & $\alpha$-Muurolene & & $2.0 \pm 0.1$ & RI, MS \\
\hline 19 & 1529 & 1530 & $\delta$-Cadinene & & $9.8 \pm 0.2$ & $\mathrm{RI}, \mathrm{MS}$, Std \\
\hline 20 & 1535 & 1537 & $\alpha$-Cadinene & & $1.4 \pm 0.1$ & $\mathrm{RI}, \mathrm{MS}$ \\
\hline 21 & 1542 & 1545 & Germacrene B & & $2.1 \pm 0.2$ & $\mathrm{RI}, \mathrm{MS}$ \\
\hline 22 & 1545 & 1543 & $\nu$-Cadinene & & $0.2 \pm 0.2$ & $\mathrm{RI}, \mathrm{MS}$ \\
\hline 23 & 1546 & 1545 & Elemol & & $1.8 \pm 0.2$ & RI, MS \\
\hline 24 & 1570 & 1570 & Globulol & & $2.0 \pm 0.1$ & RI, MS \\
\hline 25 & 1575 & 1575 & Spathulenol & & $2.2 \pm 0.2$ & RI, MS \\
\hline 26 & 1592 & 1595 & Viridiflorol & & $12.3 \pm 0.2$ & RI, MS, Std \\
\hline 27 & 1602 & 1602 & Guaiol & & $1.0 \pm 0.1$ & $\mathrm{RI}, \mathrm{MS}$ \\
\hline 28 & 1635 & 1635 & t-Muurolol & & $0.2 \pm 0.2$ & RI, MS \\
\hline 29 & 1652 & 1650 & $\alpha$-Cadinol & & $2.5 \pm 0.1$ & RI, MS \\
\hline 30 & 1654 & 1652 & $\alpha$-Eudesmol & & $3.2 \pm 0.2$ & $\mathrm{RI}, \mathrm{MS}$ \\
\hline \multirow[t]{5}{*}{31} & 1682 & 1685 & $\alpha$-Bisabolol & & $0.5 \pm 0.1$ & $\mathrm{RI}, \mathrm{MS}$ \\
\hline & & & & Monoterpene hydrocarbons & 3.7 & \\
\hline & & & & Oxygenated monoterpenes & 5.7 & \\
\hline & & & & Sesquiterpene hydrocarbons & 59.2 & \\
\hline & & & & Oxygenated sesquiterpenes & 25.7 & \\
\hline
\end{tabular}

Total identified 94.3

a Linear retention index, experimentally determined using homologous series of $\mathrm{C}_{6}-\mathrm{C}_{30}$ alkanes. binear retention index taken from Adams (2007). cRelative percentage values are means of three determinations \pm SD. didentification methods: Std, based on comparison with authentic compounds; MS, based on comparison with Wiley, Adams, FFNSC2, and NIST08 MS databases; RI, based on comparison of calculated RI with those reported in Adams, FFNSC2 and NIST08.

The major constituents of the essential oil consisted of $\beta$-caryophyllene (24.5\%), viridiflorol (12.3\%), $\delta$ cadinene (9.8\%), and bicyclogermacrene (4.2\%). Other notable constituents included $\alpha$-amorphene (3.5\%), $\alpha$-eudesmol (3.2\%), aromadendrene (2.5\%), $\alpha$-cadinol (2.5\%), terpinen-4-ol (2.3\%), $\alpha$-terpineol (2.2\%), spathulenol (2.2\%), germacrene B (2.1\%), $\alpha$-pinene (2.0\%), $\alpha$-muurolene $(2.0 \%)$, and globulol $(2.0 \%)$. Both $\beta$ - 
caryophyllene and $\delta$-cadinene occurred in a substantial amount in the bark oil when compared to the leaf oil of the same plant species (Salleh et al., 2016a), and the majority of the bark oil constituents also occurred in the leaf oil. However, 12 constituents were not detected in the bark oil; they were $\alpha$-cedrene, $\alpha$-humulene, aromadendrene, germacrene $D, \alpha$-amorphene, cadina-1,4-diene, bicyclogermacrene, $\alpha$-muurolene, elemol, viridiflorol, guaiol, and $\alpha$-cadinol. Such differences were probably due to different genotypes and chemotypes of the plant, which may affect the content of essential oil (Salleh et al., 2014; Marjo et al., 2001).

Arachidonate 5-lipoxygenase is the key enzyme in leukotriene biosynthesis and catalyzes the initial steps in the conversion of arachidonic acid to biologically active leukotrienes. Leukotrienes are considered potent mediators of inflammatory and allergic reactions and regarding their pro-inflammatory properties, the inhibition of 5-lipoxygenase pathway is considered to be interesting in the treatment of a variety of inflammatory diseases. Besides 5-lipoxygenase inhibitors, drugs able to block the 5-lipoxygenase as well as the cyclooxygenase metabolic pathway are also of therapeutic value. The LOX inhibitory effect of essential oil extracted from the bark was modest at inhibition of $60.2 \%$, compared to that of quercetin with inhibition of $92.5 \%$. Since sesquiterpene hydrocarbons of essential oils extracted from various plant species (e.g., Syzygium aromaticum, Cannabis sativa, Rosmarinus officinalis, and Tagetes minuta) were generally reported to show anti-inflammatory effect (Gertsch et al., 2008; Ghiasvand et al., 2011), thus, the high amount of $\beta$ caryophyllene and $\delta$-cadinene in the essential oil of $A$. peduncularis might at least partially contribute to the anti-inflammatory potential.

This study provides valuable and useful information and indications for further exploring the potential nutraceutical and pharmaceutical applications of the genus Lauraceae. The next step will be to evaluate the in vivo of the essential oil in order to valorize this species with a special ecological character.

\section{ACKNOWLEDGMENT}

The authors would like to thank the Fundamental University Research Grant (GPUF) for financial support under vote 2019-0225-103-01 and the Department of Chemistry, Faculty of Science and Mathematics, Universiti Pendidikan Sultan Idris for research facilities.

\section{CONFLICTS OF INTEREST}

The authors have no conflicts of interest to declare.

\section{REFERENCES}

Adams, R. P. (2007). Identification of Essential oil Components by Gas chromatography/Mass spectroscopy. Carol Stream (IL): Allured.

Gertsch, J., Leonti, M., Raduner, S., Racz, I., Chen, J. Z., Xie, X. Q., Altmann, K. H., Karsak, M., Zimmer, A. (2008). Betacaryophyllene is a dietary cannabinoid. Proceedings of the National Academy of Sciences of the United States of America, 105, 9099-9104.

Ghiasvand, A. R., Nasseri, M., Farsizaeh, S., Meshkatalsadat, M. H., Sadeghi-Sarabi, R., Shadabi, S., Borzoei, M. (2011). Chemical characterization of cultivated Tagetes minuta L. by use of ultrasound-assisted headspace SPME and GC-MS. Chromatographia, 73, 1031-1035.

Marjo, K., Eija, P., James, E. S. (2001). Variation in volatile compounds from tansy (Tanacetum vulgare L.) related to genetic and morphological differences of genotypes. Biochemical Systematics and Ecology, 29, 267-85.

Ng, F. S. P. (1989). Malayan forest records, tree flora of Malaya. Kuala Lumpur, Malaysia: FRIM, 4:98.

Salleh, W. M. N. H. W., Ahmad, F., Sirat, H. M., Khong, H. Y. (2012). Chemical compositions and antibacterial activity of the leaf and stem oils of Piper porphyrophyllum (LINDL.) N.E.Br. EXCLI Journal, 11, 399-406. 
Salleh, W. M. N. H. W., Ahmad, F., Khong, H. Y. (2014). Chemical composition of Piper stylosum Miq. and Piper ribesioides Wall. essential oils and their antioxidant, antimicrobial and tyrosinase inhibition activities. Latin American and Caribbean Bulletin of Medicinal and Aromatic Plants, 13(5), 488-497.

Salleh, W. M. N. H. W., Ahmad, F. (2016a). Antioxidant and anticholinesterase activities of essential oil of Alseodaphne peduncularis Meisn. Turkish Journal of Pharmaceutical Sciences, 13(3), 347-350.

Salleh, W. M. N. H. W., Ahmad, F. (2016b). Antioxidant and anti-inflammatory activities of essential oils of Actinodaphne macrophylla and A. pruinosa (Lauraceae). Natural Product Communications, 11(6), 853-855.

Salleh, W. M. N. H. W., Ahmad, F., Khong, H. Y., Zulkifli, R. M. (2016c). Anticholinesterase and anti-inflammatory constituents from Beilschmiedia pulverulenta Kosterm. Natural Product Sciences, 22, 225-230.

Thakur, B. K., Anthwal, A., Rawat, D. S., Rawat, B., Rashmi, Rawat, M. S. M. (2012). A review on genus Alseodaphne: phytochemistry and pharmacology. Mini-Reviews in Organic Chemistry, 9, 433-445.

Turner, I. M. (1995). A catalogue of the Vascular Plants of Malaya. Gardens' Bulletin Singapore, 47(1), 1-346. 